www.jmscr.igmpublication.org Impact Factor 5.244

Index Copernicus Value: 83.27 ISSN (e)-2347-176x ISSN (p) 2455-0450 crossref DOI: https://dx.doi.org/10.18535/jmscr/v5i1.07

\title{
Is Glucose-6-Phosphate Dehydrogenase Deficiency a Risk Factor for Proliferative Diabetic Retinopathy in Male Patients with Type 1 Diabetes Mellitus in Basrah?
}

\author{
Authors \\ Hussein Ali Nwayyir- MD ${ }^{1}$, Abbas Ali Mansour - MD, FRCP, FACE ${ }^{2}$ \\ ${ }^{1}$ Al-Faiha Specialized Diabetes, Endocrine, and Metabolism Center (FDEMC), Basrah - 61013, Iraq \\ ${ }^{2}$ Endocrine and Metabolism Division, Dept of Medicine, Basrah College of Medicine, Basrah - 61013, Iraq \\ Ccorresponding Author
}

Professor Abbas Ali Mansour -MD, FRCP, FACE

Consultant Endocrinologist, Al-Faiha Specialized Diabetes, Endocrine, and Metabolism Center (FDEMC), Chair Diabetes, Endocrine and Metabolism Division, Department of Medicine, Basrah College of Medicine

Hattin Post office P.O Box: 142, Basrah - 61013 Iraq

Emailaambaam@gmail.com, Phone009647801403706

\begin{abstract}
Background: Diabetes Mellitus is a chronic and common disease with diabetic retinopathy a frequent long-term complication.Glucose-6-phosphate dehydrogenase (G6PD) deficiency is the most prevalent human enzyme defect. Both of these conditions are very common in our locality with many burdens on the patients' quality of life and health care services.
\end{abstract}

Aim: To search for any significant association between G6PD deficiency and the development of proliferative diabetic retinopathy (PDR) among male patient with type 1 diabetes mellitus (T1DM).

Method: A case-control study was conducted onNinety-four adult male patients with T1DM in Al Faiha Diabetes, Endocrine and Metabolism Center over a two-year period from October 2012 to October 2014. All patients are submitted to both funduscopicexaminations of their eyes and G6PD assay.

Results: PDR is found among $7.6 \%$ of those who were G6PD sufficient in comparison to $42.9 \%$ of G6PD deficient ( $p$-value $<0.001$ ).

Conclusion: There is a significant association between G6PD deficiency status and the development of PDR in male patients with TIDM.

Keywords: type 1 diabetes mellitus, Glucose-6-phosphate dehydrogenase (G6PD) deficiency, and proliferative diabetic retinopathy.

\section{Introduction}

Type 1 diabetes mellitus (T1DM) is a chronic medical condition in which genetically susceptible subjects had their pancreatic $\beta$-cells destructed by autoimmune process which results in absolute insulin deficiency. This disease is diagnosed between infancy and adulthood and is clinically manifested by polyuria, polydipsia, and weight loss associated with glycosuria and ketonuria. ${ }^{1}$ 
T1DM is the usual type of diabetes in youth, accounting for morethan $85 \%$ of all diabetes cases in youth< 20 years of age worldwide..$^{2,3,4}$, In general, the incidence rate increases from birth and peaks between the ages of 10-14 years during puberty. ${ }^{5, \underline{7} 7}$ The increasing incidence of T1DM throughout the world is especially marked in young children. $\underline{6}, \underline{8}$

Diabetic retinopathy is a microvascular complication of diabetes with a considerable risk of blindness. Global population-based data indicate that it is the fifth most common cause of blindness in the world, accounting for approximately $4.8 \%$ of global blindnessand considered as a leading cause of blindness in industrialized countries, ${ }^{9}$ and its significance is likely to increase with increasing frequency of diabetes. ${ }^{10}$

The strong relationship between chronic hyperglycemia and the development and progression of diabetic retinopathy had been confirmed by the Diabetes Control, and Complications Trial (DCCT) and United Kingdom Prospective Diabetes Study (UKPDS) clinical trialsbut the exact underlying mechanism that is responsible for the development of microvascular disease as a result of hyperglycemia remains unclear. $^{11,12}$

Glucose-6-phosphate dehydrogenase (G6PD) deficiency is the most prevalent enzyme deficiency in the world, with an estimated $>400$ million people with G6PD deficiency. G6PD deficiency is common throughout sub-Saharan Africa, regions in the Mediterranean, and parts of Southeast Asia. ${ }^{13,14}$

The relationship between diabetes and G6PD deficiency is still a matter of debate. The theory that chronic hyperglycemia can cause a decrease in G6PD activity is supported by experimental observations. ${ }^{15}$ On the other hand, the reverse theoryin that G6PD deficiency could be a risk factor for the occurrence of diabetes has also been raised. In several populations, individuals with diabetes had increased prevalence of G6PD deficiency compared with the background rate of the general population. $\underline{15}$
Evidence indicates that patients with aG6PD deficiency are protected against ischemic heart disease, cerebrovascular disease, nonarteritic anterior ischemic optic neuropathy and retinal vein occlusion. ${ }^{16,17,18}$ On the other hand, an increased prevalence of proliferative diabetic retinopathy (PDR) in patients with G6PD deficiency and type 1 diabetes has recently been reported in a small study, raising the idea that G6PD deficiency accelerates the microvascular retinalcomplications of diabetes. ${ }^{19}$

In a recent study, it was found that in diabetic men with PDR the prevalence of G6PD deficiency was lower than in age-matched non-diabetic controls and that G6PD deficiency showed a tendency for protection against PDR in diabetic individuals, but the results were not statistically significant. ${ }^{20}$

As diabetes mellitus become a global pandemic, especially in middle eastern countries, 21,22,23 together with the rapid increase in the incidence of T1DM, ${ }^{6,7,8,24}$ it is curious to find the various associations with that disease. As G6PD was the commonest enzyme deficiency, ${ }^{13,14}$ then it was important to see the association between these two common implications for the human being.

\section{Aim of the study}

To search for any significant association between G6PD deficiency and the development of PDR among male patients with T1DM.

\section{Patients and Methods}

Ninety-four male patientsare enrolled in this CaseControl study, who were regular attendants atthe Al Faiha Endocrine, Diabetes and Metabolism Center for both G6PD assay and concomitant funduscopic eye examination during the time intervalbetween October 2012 andOctober 2014.

The ethical committee of the Basrah College of Medicine approved the study, and verbal informed consent was taken from patients.

The general characteristics of the (case and control groups) were assessed for: age of the patient, duration of T1DM, Level and number of glycosylated hemoglobin (HbAlc) measurements over the last three years, Systolic and diastolic 
pressures, intraocular pressures in both eyes and the prevalence of complications in terms of albuminuria, diabetic retinopathy, PDR, and maculopathy.

Type 1 diabetes was defined by time of diagnosisless than 40 years, C-peptide less than or equal to $0.3 \mathrm{nmol} / \mathrm{L}$ or starting insulin treatment within one year of diagnosis if C-peptide was not measured andpositive anti-glutamate decarboxylase antibody (anti-GAD), islet cell or insulin antibodies. ${ }^{25,26,27}$

The inclusion criteria are being male with T1DM with duration of more than ten years.

Those patients with chronic kidney disease, age below 16 years, duration of diabetes less than ten years, and those who are smokers were excluded from the study.

The (cases) are male patients who had T1DM of more than or equal to10 years and are G6PD deficient while the (controls) are male patients who had T1DM of more than or equal to 10years and are G6PD sufficient.

The G6PD assay method that was used in this study is the old traditional colorimetric assay in which RBCs were treated with nitrite and so converting oxyhemoglobin [red] into methemoglobin [brown], then examining the rate of NADPH-dependent methemoglobin reduction in the presence glucose as a substrate and an appropriate radix catalyst (Nile blue or methylene blue). ${ }^{28,29}$

The funduscopic eye examination was conducted at (Al Faiha Ophthalmology Consultation Clinic) with both direct and indirect ophthalmoscope done by the consultant ophthalmologist according to the 2011 Scottish Diabetic Retinopathy Grading Scheme. ${ }^{30}$ (Appendix)

\section{Statistical Analysis}

The data obtained from this study were analyzed using the Statistical Package for Social Sciences (SPSS) software version 20.0, descriptive analysis was done using (mean \pm standard deviation), (frequency) and (percentage of each value), with the ( $p$-value of less than 0.05 ) to be considered as significant.

\section{Results}

Ninety-four patients with T1DMwere enrolled with a mean age of (27.66 \pm 8.69 years), and a mean duration of T1DM (15.3 \pm 3.32 years $)$. Among them, the number of patients who were G6PD deficient was 28 patients (29.8\%).

The general characteristics of the (case and control groups) in terms of age, duration of diabetes, level and number of $\mathrm{HbAlc}$ measurements over the last 3 years, systolic and diastolic pressures and intraocular pressures in both eyes together with the prevalence of complications in terms of albuminuria, diabetic retinopathy, PDR and maculopathy are shown in (Table 1).

In the studiedgroup, diabetic retinopathy was seen in 38 patients $(40.4 \%)$, and those who had normal retinal examination were56 patients $(59.6 \%)$.

Of those 66 patients who were G6PD sufficient (Table 2, Fig. 1), $40(60.6 \%)$ had no retinopathy in comparison to 26 (39.4\%) had retinopathy, while among those 28 patientswho were G6PD deficient,it was found that $16(57.1 \%)$ had no retinopathy in comparison to $12(42.9 \%)$ patients had retinopathy (p-value $=0.820)$.

Table 3 (Fig.2) illustrated the association of G6PD deficiency with the prevalence of PDR. Among the 66 patients who were(G6PD sufficient), there were five patients $(7.6 \%)$ had proliferative retinopathy, while 61 patients $(92.4 \%)$ had no evidence of proliferative retinopathy. On the other side,among the28 patients whowere(G6PD deficient), 16 patients $(57.1 \%)$ had no proliferative retinopathy in comparison to $12(42.9 \%)$ had evidence of proliferative retinopathy (pvalue $<0.001$ ). 


\section{JMSCR Vol||05||Issue||01||Page 15173-15179||January}

Table 1-Characteristics of the male diabetic patients studied and prevalence of complications

\begin{tabular}{|l|c|c|c|}
\hline Characteristic & $\begin{array}{c}\text { T1DM, } \\
\text { G6PD } \\
\text { Sufficient } \\
\boldsymbol{n = 6 6}\end{array}$ & $\begin{array}{c}\text { TIDM, } \\
\text { G6PD } \\
\text { deficient } \\
\boldsymbol{n = 2 8}\end{array}$ & $\begin{array}{c}\text { P- } \\
\text { value }\end{array}$ \\
\hline Age (years) Mean \pm SD & $29.0 \pm 9.3$ & $26.5 \pm 6.1$ & 0.119 \\
\hline $\begin{array}{l}\text { Duration of diabetes } \\
\text { (years) } \\
\text { Mean } \pm \text { SD }\end{array}$ & $15.6 \pm 3.5$ & $14.8 \pm 2.9$ & 0.313 \\
\hline $\begin{array}{l}\text { HbA1c Measurements } \\
\text { (n) } \\
\text { Mean } \pm \text { SD }\end{array}$ & $3.4 \pm 1.9$ & $4.3 \pm 3.0$ & 0.136 \\
\hline HbA1c (\%) Mean \pm SD & $10.7 \pm 2.3$ & $9.7 \pm 1.8$ & 0.122 \\
\hline $\begin{array}{l}\text { Blood Pressure, Systolic } \\
\text { (mm Hg) means } \pm \text { SD }\end{array}$ & $119.5 \pm 14.6$ & $114.3 \pm 14.8$ & 0.120 \\
\hline $\begin{array}{l}\text { Blood Pressure, Diastolic } \\
\text { (mmHg) mean } \pm \text { SD }\end{array}$ & $73.8 \pm 12.3$ & $73.4 \pm 12.6$ & 0.889 \\
\hline $\begin{array}{l}\text { Intraocular Pressure R } \\
\text { (mmHg) mean } \pm \text { SD }\end{array}$ & $14.5 \pm 1.1$ & $14.2 \pm 0.9$ & 0.157 \\
\hline $\begin{array}{l}\text { Intraocular Pressure L } \\
\text { (mmHg) mean } \pm \text { SD }\end{array}$ & $14.6 \pm 1.1$ & $14.2 \pm 0.9$ & 0.112 \\
\hline Albuminuria, n (\%) & $48(72.8)$ & $18(64.3)$ & 0.419 \\
\hline Retinopathy, any n (\%) & $26(39.4)$ & $12(42.9)$ & 0.820 \\
\hline $\begin{array}{l}\text { Retinopathy, } \\
\text { Proliferative (\%) }\end{array}$ & $5(7.6)$ & $12(42.9)$ & 0.001 \\
\hline Maculopathy n (\%) & $1(1.5)$ & $7(25)$ & 0.010 \\
\hline
\end{tabular}

Table 2-Association between diabetic retinopathy and G6PD deficiency

\begin{tabular}{|c|c|c|c|c|}
\hline & \multicolumn{2}{|c|}{ Retinopathy $n(\%)$} & \multirow{2}{*}{$\begin{array}{l}\text { Total } \\
n(\%)\end{array}$} \\
\hline & & No & Yes & \\
\hline \multirow{2}{*}{$\begin{array}{l}\text { G6PD } \\
\text { Deficiency }\end{array}$} & No & $40(60.6)$ & $26(39.4)$ & $66(70.2)$ \\
\hline & Yes & $16(57.1)$ & $12(42.9)$ & $28(29.8)$ \\
\hline \multicolumn{2}{|l|}{ Total } & $56(59.4)$ & $38(40.6)$ & 94 \\
\hline
\end{tabular}

Table 3-Association between proliferative retinopathy and G6PD deficiency

\begin{tabular}{|c|c|c|c|c|}
\hline & \multicolumn{2}{|c|}{$\begin{array}{c}\text { Proliferative } \\
\text { Retinopathy } n(\%)\end{array}$} & \multirow[t]{2}{*}{$\begin{array}{l}\text { Total } \\
n(\%)\end{array}$} \\
\hline & & No & Yes & \\
\hline \multirow[t]{2}{*}{$\begin{array}{l}\text { G6PD } \\
\text { Deficiency }\end{array}$} & No & $61(92.4)$ & $5(7.6)$ & $\begin{array}{c}66 \\
(70.2)\end{array}$ \\
\hline & Yes & $16(57.1)$ & $12(42.9)$ & $\begin{array}{c}28 \\
(29.8)\end{array}$ \\
\hline \multicolumn{2}{|l|}{ Total } & $77(81.9)$ & $17(18.1)$ & 94 \\
\hline
\end{tabular}

Figure 1-Association between diabetic retinopathy and G6PD deficiency

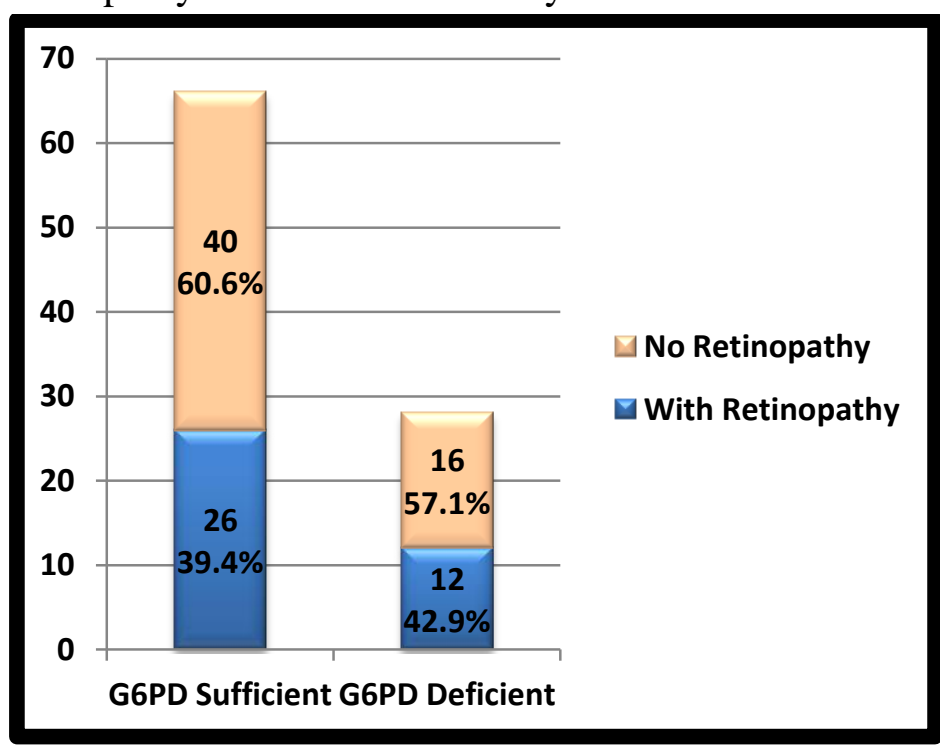

Figure 2-Association between proliferative retinopathy and G6PD deficiency

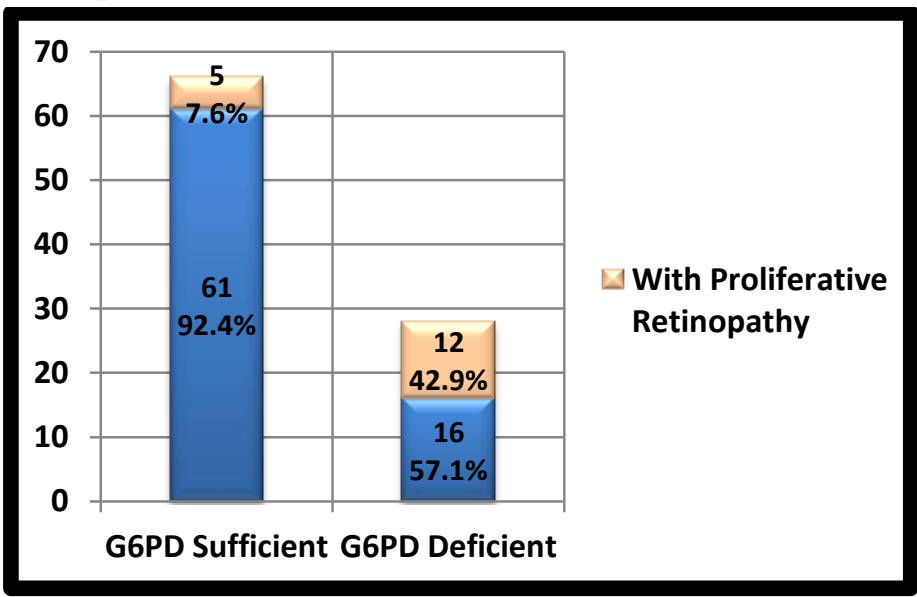

\section{Discussion}

The prevalence of G6PD deficiency among Iraqi people was 7-9.9\%, according to World Health Organization data, ${ }^{14}$ However, inthisstudy G6PD deficiency was seen in $29.8 \%$ because its highly selective study with a limited number of patients and thus did not reflect the exact prevalence of G6PD among Iraqi people.

During the last 20 years, many studies had published on the effect of G6PD deficiency on many of the human diseases, including malaria ${ }^{31}$, cardiovascular disease ${ }^{18,32}$, and retinal vein occlusion. ${ }^{17}$ This study did notfind an increased prevalence of diabetic retinopathy among patients who are G6PD deficient (p-value of 0.820). 
A significant association was seen between G6PD deficiency and the development of PDR ( $p$ value $<0.001$ ) which is similar to Cappai et al, who studiedpatients with G6PDdeficiency or sufficiency with more than fifteen years history of T1DM for whom HbA1c records were available for at least the previous three years,smoking and renal failure were exclusion criteriaand they find that PDR was onlyfounded in individuals with G6PD deficiency. ${ }^{19}$

On the other hand, Pinna A etal., hadconcluded that the prevalence of G6PD deficiency in diabetic males with PDR was lower than in age-matched non-diabetic controls, and G6PD deficiency showed a tendency for protection against PDR in diabetic individuals, but the results were not statistically significant,and they enrolled type 1 and type 2 patients with age more than 50 years. ${ }^{20}$ The main study limitation was the non-availability of the field colored photographs for retinal examination for the standardization purposes. With the method that was used for the G6PD assay was a crude qualitative method. And it's a single-center study with a small number of patients.

\section{Conclusion}

No associationwas found between the prevalence of diabetic retinopathy and G6PD status, but once retinopathy developed there is a significant association with the development of PDR among those who are G6PD deficient indicating that G6PD deficiency is a risk factor for the development of PDR in male patients with T1DM. G6PD could be measured inmales with T1DM, as it may be a marker of subsequent proliferative retinopathy.

Conflict of interest: None declared

Author Contributions: Both authors contributed equally to the study.

\section{References}

1. Merger SR, Leslie RD and Boehm BO. The broad clinical phenotype of type 1 diabetes at presentation. Diabetic Medicine. 2013; 30:170-8.

2. Liese AD, D’Agostino RB Jr., Hamman RF, Kilgo PD, Lawrence JM, Liu LL et al. The burden of diabetes mellitus among US youth: prevalence estimates from the SEARCH for Diabetes in Youth Study. Peds. 2006;118:1510-8.

3. Vandewalle CL, Coeckelberghs MI, De Leeuw IH, Du Caju MV, Schuit FC, Pipeleers DGet al. Epidemiology, clinical aspects, and biology of IDDM patients under age 40 years. Comparison of data from Antwerp with complete ascertainment with data from Belgium with $40 \%$ ascertainment. The Belgian Diabetes Registry. Diabetes care. 1997;20:1556-61.

4. Thunander M, Petersson C, JonzonK, Fornander J, Ossiansson B, Torn C et al. Incidence of type 1 and type 2 diabetes in adults and children in Kronoberg, Sweden. Diabetes Res Clin Pract. 2008;82:247-55.

5. Dabelea D, Bell RA, D'Agostino RB Jr, Imperatore $\mathrm{G}$, Johansen $\mathrm{JM}$, Linder $\mathrm{B}$ et al. Incidence of diabetes in youth in the United States. JAMA.2007;297:2716-24.

6. DIAMOND Project Group.Incidence and trends of childhood Type 1 diabetes worldwide 1990-1999. Diabet Med. 2006; 23:857-66.

7. EURODIAB ACE Study Group. Variation and trends in incidence of childhood diabetes in Europe. Lancet.2000;355:873-6.

8. Patterson CC, Dahlquist GG, Gyurus E, Green A and Soltesz G. Incidence trends for childhood type 1 diabetes in Europe during 1989-2003 and predicted new cases 2005-20: a multicentre prospective registration study. Lancet. 2009;373:2027-33.

9. Resnikoff S, Pascolini D, Etya'ale D, Kocur I, Pararajasegaram R, Pokharel GP et al. Global data on visual impairment in the year 2002. Bull World Health Organ 2004; 82:844-51. 
10. Kempen JH, O'Colmain BJ, Leske MC, Haffner SM, Klein R, Moss SE et al. The prevalence of diabetic retinopathy among adults in the United States. Archives of Ophthalmology. 2004;122:552-63.

11. Matthews DR, Stratton IM, Aldington SJ, Holman RR, Kohner EM. Risks of progression of retinopathy and vision loss related to tight blood pressure control in type 2 diabetes mellitus: UKPDS 69. Archives of Ophthalmology. 2004; 122(11):1631-40.

12. White NH, Cleary PA, Dahms $\mathrm{W}$, Goldstein D, Malone $\mathrm{J}$ and Tamborlane WV. Beneficial effects of intensive therapy of diabetes during adolescence: Outcomes after the conclusion of the Diabetes Control and Complications Trial (DCCT). The Journal of Pediatrics.2001; 139(6):804-12.

13. Cappellini MD and Fiorelli G. Glucose-6phosphate dehydrogenase deficiency. Lancet. 2008;371:64-74.

14. World Health Organization Working Group. Glucose-6-phosphate dehydrogenase deficiency. WHO Working Group. Bull World Health Organ. 1989;67:601-11.

15. Carette C, Dubois-Laforgue D, Gautier JF and Timsit J. Diabetes mellitus and glucose-6-phosphate dehydrogenase deficiency: from one crisis to another. Diabetes Metab. 2011;37:79-82.

16. Cocco P, Todde P, Fornera S, Manca MB, Manca M, Sias AR. Mortality in a cohort of men expressing the Glucose-6Phosphate Dehydrogenase deficiency. Blood. 1998;91:706-9.

17. Pinna A, Carru C, Solinas G, Zinellu A and Carta F. Glucose-6-phosphate dehydrogenase deficiency in retinal vein occlusion. Invest Ophthalmol Vis Sci. 2007;48:2747-52.

18. Meloni L, Manca MR, Loddo I, Cioglia G, Cocco P, Schwartz Aet al. Glucose-6phosphate dehydrogenase deficiency protects against coronary heart disease. J Inherit Metab Dis. 2008;31:412-7.

19. Cappai G, Songini M, Doria A, Cavallerano JD and Lorenzi M. Increased prevalence of proliferative retinopathy in patients with type 1 diabetes who are deficient in glucose-6-phosphate dehydrogenase. Diabetologia.2011;54:1539-42.

20. Pinna A, Contini EL,Carru C and Solinas G. Glucose-6-Phosphate Dehydrogenase Deficiency and Diabetes Mellitus with Severe Retinal Complications in a Sardinian Population, Italy.Int J Med Sci. 2013;10(13):1907-13.

21. Lozano R, Naghvi M, Foreman K, Lim S, Shibuya K, Aboyans V, et al. Global and regional mortality from 235 causes of death for 20 age groups in 1990 and 2010: A systematic analysis for the Global Burden of Disease Study 2010. Lancet. 2012;380:2095-128.

22. Das P and Samarasekara U. The story of GBD 2010: A "super human" effort. Lancet. 2012;380:2067-70.

23. Vos T, Flaxman AD, Naghvi M, Lozano R, MicahudC, Ezzati $M$ et al. Years lived with disability (YLDs) for 1160 sequelae of 289 diseases and injuries 1990-2010: A systematic analysis for the Global Burden of Disease Study 2010. Lancet. 2012;380:2163-96.

24. Diabetes Epidemiology Research International Group Secular trends in incidence of childhood IDDM in 10 countries. Diabetes. 1990;39:858-64.

25. Lithovius R , Harjutsalo V, Forsblom C and Groop PH.Cumulative cost of prescription medication in outpatientswith type 1 diabetes in Finland. Diabetologia. 2011;54:496-503.

26. Asian-Pacific Type 2 Diabetes Policy Group. Type 2 Diabetes Practical Targetsand Treatments. Screening, Diagnosis, Management, Treatment, Monitoring, Education, Prevention. Fourth edition. 2005. 
27. World Health Organization Department of Non-communicable Disease Surveillance. Definition, Diagnosis, and Classification of Diabetes Mellitus and its Complications. Geneva. 1999

28. Brewer GJ, Tarlov A,and Alving A. Methaemoglobin reduction test: a new, simple, in vitro test for identifying primaquine-sensitivity. Bull World Health Organ. 1960;22:633-40.

29. Beutler Eand Baluda MC. Methemoglobin Reduction: Studies of the interaction between cell populations and of the role of methylene blue. Blood. 1963;22:323-33.

30. Scottish Diabetic Retinopathy Screening Collaborative. National diabetes retinopathy screening. Available fromwww.ndrs.scot.nhs.uk.

31. Cappadoro M, Giribaldi G, O'Brien E, Turrini F, Mannu F, Ulliers D et al. Early phagocytosis of glucose-6-phosphate dehydrogenase (G6PD)-deficient erythrocytes parasitized by Plasmodium falciparum may explain malaria protection in G6PD deficiency. Blood. 1998;92:2527-34.

32. Nikolaidis MG, Jamurtas AZ, Paschalis V, Kostaropoulos IA, Kladi-Skandali A, Vera Balamitsi $\mathrm{V}$ et al. Exercise-induced oxidative stress in G6PD-deficient individuals. Med Sci Sports Exerc 2006;28:144350. 